\title{
Anterior Cervical Discectomy, Fusion and stabilization by plate and screw-early experience
}

\author{
Islam MA ${ }^{1}$, Islam $\mathrm{MA}^{2}$, Habib MA ${ }^{3}$, Sakeb $\mathrm{N}^{4}$ \\ ${ }^{1}$ Assistant Professor, ${ }^{2}$ Medical Officer, Department of Orthopaedic Surgery, Bangabandhu Sheikh \\ Mujib Medical University (BSMMU), Dhaka, ${ }^{3}$ Department of Neurology, BSMMU, Dhaka, \\ ${ }^{4}$ Resident, Department of Orthopaedic Surgery, BSMMU, Dhaka. \\ Email: anowar.ortho@gmail.com
}

\begin{abstract}
Anterior cervical plating is commonly performed to stabilize anterior cervical fusion. The aim of the study was to evaluate the clinical and functional outcome, radiological fusion and operative complications in cases of cervical spondylotic myelopathy and radiculopathy who underwent Anterior Cervical Discectomy and Fusion (ACDF) by autograft and stabilized with plate and screw. We evaluated 16 consecutive patients (M: F=10:6) from January 2008 to December 2010 in Bangabandhu Sheikh Mujib Medical University (BSMMU) and different private hospitals in Dhaka, in cases where adequate conservative treatment failed. Single level ACDF by autograft and stabilization by plate and screw was done in 10 patients and 06 patients had two levels fusion. The mean follow up period was 18 months. The patients improved significantly $(\mathrm{p}<0.05)$ and the recovery rate was $87.50 \%$. All patients showed radiological fusion $(\mathrm{p}<0.001)$. There was no hardware failure, graft extrusion or plate breakage. ACDF with plate and screw is fairly safe and effective therapy for cervical disc degeneration leading to myelo-radiculopathy where major post operative complications are uncommon.
\end{abstract}

\section{Introduction}

Cervical spondylotic myelo-radiculopathy (CSMR) is a spinal cord dysfunction (SCD) accompanying typical age related degeneration of the cervical spine $^{1}$. Myelopathic or upper motor neuron lesion (UMNL) findings (e.g. hyperreflexia and gait disturbance) are the typical manifestations and the most common cause of SCD after 55 years ${ }^{2}$. Other manifestation is radiculopathy due to degenerative process that leads to loss of disc height; annulus bulge/tear and herniation of disc material to produce pressure effect over the cord and roots ${ }^{3}$. Instability by altered biomechanics of the cervical spinal column invites inflammatory reparative process which produces arthritic pain and facet hypertrophy leading to spur formation ${ }^{2}$.

Neck or shoulder pain with radiation to one or both upper limbs, tingling, numbness or weakness in the hand is common presenting symptoms of cervical radiculopathy. Features of myelopathy include, altered gait, muscle weakness, bladder/ bowel dysfunction, reduced fine motor skills, which all depends upon the location of compression.
Myelopathic hand, Grip release sign (Patient is unable to make and release a fist more than 20 times in 10 seconds), Hoffman's sign, Romberg test along with gait disturbances (broad based and hesitant) are common in severe conditions. Changes in the pattern of bladder and bowel dysfunction are the key components of the history found in $20 \%-50 \%$ of the patients ${ }^{4}$.

Anterior cervical discectomy and fusion (ACDF) has first been introduced by Bailey and Badgley, Smith and Robinson ${ }^{6}$ and Cloward ${ }^{7}$ in the 1950s and early 1960s for degenerative diseases of the cervical spine. To overcome the graft related complications (e.g., graft compression fracture, graft resorptions or dislocation and pseudoarthrosis) anterior plating to the treated segment is highly recommended ${ }^{8}$. Anterior plate and screw constructs provides enhanced stability and maintenance of deformity correction, lordotic curvature and increases the stability and probability of fusion, compared to no plates and it may eliminate the need for rigid collar immobilization postoperatively 9 . Though use of plate for single 
level ACDF is controversial but it is the most common operative technique for CSMR due to degenerative cervical disease ${ }^{\mathbf{1 0}}$.

There had been few studies in our country where outcome of non-instrumented and instrumented ACDF in varieties of cervical disorders has been analyzed but there had been no study assessing the outcome of this technique in CSMR. The aim of this study was to analyze the clinical and functional outcome, fusion and overall complications of surgery in this common cervical disorder.

\section{Materials and Methods}

This study is a consecutive case review of 16 patients who underwent instrumentation at single and two level anterior cervical discectomy and fusion with autogenous tricortical iliac crest graft and plating in locking mode from January 2008 to December 2010 in Bangabandhu Sheikh Mujib Medical University and different other private clinics in Dhaka. Ten patients had single and 6 patients had two level fusion. All patients had clinical evidence of cervical radiculopathy or myelopathy or both, unresponsive to conservative treatment with MRI confirmation of nerve root impingement and cord compression in degenerative disease of the cervical spine. Listhesis, tumor and tuberculosis were excluded from history, clinical examinations and investigations.

Plain X-ray (taken in the upright position) in AP view showed joint space narrowing or sclerosis, lateral view showed disc space narrowing, end plate osteophytes, loss of lordosis or spondylolisthesis. Ossified Posterior Longitudinal ligament (OPLL), a solid line of bone immediately behind the vertebral bodies was also seen in lateral view. Flexion-extension views of the lateral x-ray showed increase motion at spondylosis or listhesis. MRI was done in all patients in severe unremitting neck pain with failed conservative treatment and or progressive neurological deficits. Radiographic determination of union and osseous incorporation based on, 1) continuity of the trabecular and/or complete osseous union at the graft/ bone interface 2) absence of luscencies or halo formation around the graft with the presence of bridging bone. We assessed pain status improvement by Visual Analogue Score (VAS) ${ }^{\mathbf{1 1}}$, the clinical outcome (sensory, motor and reflex) by the clinical tests and overall functional outcome with modified Odom's criteria $^{\mathbf{8}}$ (Table-I). We focused on operating room time, hospital stay, intra and postoperative complications, outcome and time to return to normal activities including work. No patient had previous cervical spine surgery. Patients were discharged with soft cervical collar for 1 month (average) and began range of motion exercise as shortly as pain subsided. Depending on the level of job activity patient were instructed to resume normal activities which was 6 weeks for moderate labor and 12 weeks for job required heavy labor and 3 weeks if the job required minimal labor. Postoperative evaluation included examinations and lateral cervical spine radiograph at 3, 6, 12 weeks, and 6 months and then annually to assess solid fusion and progressed bony incorporation at the graft vertebral interface.

The technique used was a modification of the procedure as originally described by Smith and Robinson ${ }^{6}$. Briefly, a transverse right sided cervical incision was used for exposure. All the disc material and posterior osteophytes were removed. Posterior longitudinal ligament was removed at the intervertebral space. Autogenous tricortical bone graft taken from the iliac crest, sized positioned and fixed with locking cervical plate.

\section{Results}

Sixteen consecutive patients of cervical spondylosis were treated. Mean age of the patients was 45 years (range 35-55yrs). There were 10(62.50\%) male and $06(37.50 \%)$ female (Table-II). Mean duration of symptoms was 1.5 years and follow up was 18 months (range 12-30 months). Average operating room time was 2.5 hours and average hospital stay was 3 days and average time to return to normal activities was 3 weeks. Neck and arm pain improved significantly $(\mathrm{p}<0.001)$ post operatively as well as the sensory, motor and reflex status $(\mathrm{p}<0.05)$.

Average time of union was 3.5 months (range 3-9 months). Outcome was satisfactory in $14(87.50 \%)$ patients with no poor results in the series (TableIII) and no patients required further surgery in the same level. Radiological fused levels were at C4-5 04(25.00\%); at C5-6 08(50.00\%); at C5-6, C6-7 $03(18.75 \%)$ and at C6-7 01(06.25\%) (Table-IV).

As described in Table- $\mathrm{V}$, complications were donor site morbidity in $03(18.75 \%)$ patients, which improved at 4 months; causes were fracture of the ilium, infection, haematoma. Dysphagia was found in $02(12.50 \%$ ) patients which was mild and self limited. There was no dysphonia, pseudoarthrosis or deformity due to graft subsidence, graft dislodgement, plate loosening or breakage, screw migration or misdisplacment, and CSF leakage. There was no deterioration of neurological symptoms and adjacent segment disease. 
Table I: Assessment criteria for overall functional outcome

\begin{tabular}{cc}
\hline & Modified Odom's criteria \\
\hline Excellent & $\begin{array}{c}\text { No complaints related to cervical lesion, with a smooth } \\
\text { return to daily activities and work }\end{array}$ \\
Food & $\begin{array}{c}\text { Intermittent complaints related to the cervical lesion } \\
\text { without any serious difficulties in performing daily } \\
\text { activities and work }\end{array}$ \\
& $\begin{array}{c}\text { Patients satisfied with improvement of subjective } \\
\text { symptoms but with difficulties in performing daily } \\
\text { activities and work }\end{array}$ \\
& deterioration or no improvement of symptoms after \\
surgery
\end{tabular}

Table II: Patients demographic data $(n=16)$

\begin{tabular}{|c|c|c|c|c|c|c|c|c|}
\hline \multicolumn{2}{|c|}{ Age (yrs.) } & \multirow[t]{2}{*}{ Mean } & \multicolumn{3}{|c|}{ Sex } & \multicolumn{3}{|c|}{ Occupation } \\
\hline $35-40$ & 03 & & Male & 10 & $62.50 \%$ & $\begin{array}{l}\text { Sedentary } \\
\text { worker }\end{array}$ & 07 & $43.75 \%$ \\
\hline $40-45$ & 06 & \multirow[t]{3}{*}{45} & Female & 06 & $37.50 \%$ & Heavy worker & 03 & $18.75 \%$ \\
\hline $45-50$ & 04 & & & & & Housewife & 06 & $37.50 \%$ \\
\hline $50-55$ & 03 & & & & & & & \\
\hline
\end{tabular}

Table III: Clinical follow up and operative outcome $(n=16)$

\begin{tabular}{|c|c|c|c|c|c|c|}
\hline \multicolumn{7}{|c|}{ Clinical Outcome } \\
\hline & & \multicolumn{2}{|c|}{ Pre operative } & \multicolumn{2}{|c|}{6 months } & 1 year \\
\hline & & \multicolumn{2}{|l|}{ No $(\%)$} & \multicolumn{2}{|c|}{ No (\%) } & No (\%) \\
\hline Neck pain & VAS & \multicolumn{2}{|l|}{$7.5 \pm 1.0$} & \multicolumn{2}{|c|}{$2.0 \pm 0.75$} & $2.0 \pm 0.5$ \\
\hline Arm pain & & \multicolumn{2}{|l|}{$8.0 \pm 0.5$} & \multicolumn{2}{|c|}{$2.5 \pm 0.75$} & $2.0 \pm 0.5$ \\
\hline Sensory & Clinical & \multicolumn{2}{|l|}{$13(81.50 \%)$} & \multicolumn{2}{|c|}{$06(37.50 \%)$} & $02(12.50 \%)$ \\
\hline Motor & tests & \multicolumn{2}{|c|}{$09(62.50 \%)$} & \multicolumn{2}{|c|}{$05(31.25 \%)$} & $02(12.50 \%)$ \\
\hline Reflex & & \multicolumn{2}{|l|}{$16(100 \%)$} & \multicolumn{2}{|c|}{$06(37.50 \%)$} & $01(06.25 \%)$ \\
\hline \multicolumn{7}{|c|}{ Functional Outcome } \\
\hline \multirow{4}{*}{\multicolumn{2}{|c|}{$\begin{array}{l}\text { Modified Odom's } \\
\text { criteria }^{8}\end{array}$}} & Excellent & 08 & $0.00 \%)$ & \multirow{2}{*}{$87.50 \%$} & \multirow{2}{*}{ Satisfactory } \\
\hline & & Good & \multicolumn{2}{|c|}{$06(37.50 \%)$} & & \\
\hline & & Fair & \multicolumn{2}{|c|}{$02(12.50 \%)$} & \multirow{2}{*}{$12.50 \%$} & \multirow{2}{*}{ Unsatisfactory } \\
\hline & & Poor & \multicolumn{2}{|c|}{$00(00.00 \%)$} & & \\
\hline
\end{tabular}

VAS=Visual analogue scale

Table IV: Level of fusion $(n=16)$

\begin{tabular}{lcc}
\hline Fused level & No of pts & Percentage(\%) \\
\hline C4-5 & 04 & 25.00 \\
C5-6 & 08 & 50.00 \\
C5-6, C6-7 & 03 & 18.75 \\
C6-7 & 01 & 06.25 \\
\hline Total & 16 & 100 \\
\hline
\end{tabular}

Table V: Complications $(\mathrm{n}=16)$

\begin{tabular}{lcc}
\hline Complications & No of pts & Percentage(\%) \\
\hline Donor site morbidity & 03 & 18.75 \\
Transient dysphagia & 02 & 12.50 \\
\hline
\end{tabular}

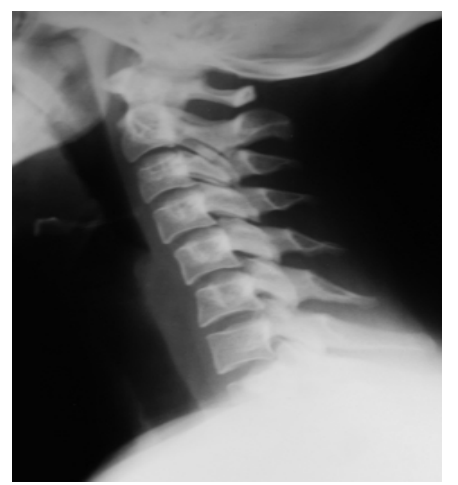

Fig.-1: Preoperative X-ray (lateral view) of cervical spondylosis involving C5-6.

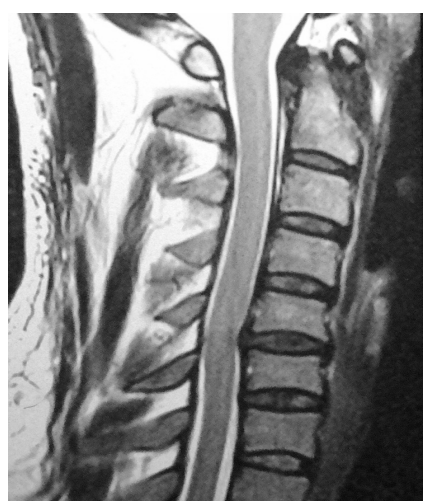

Fig.-2: MRI showing cord compression at C5-6 level.

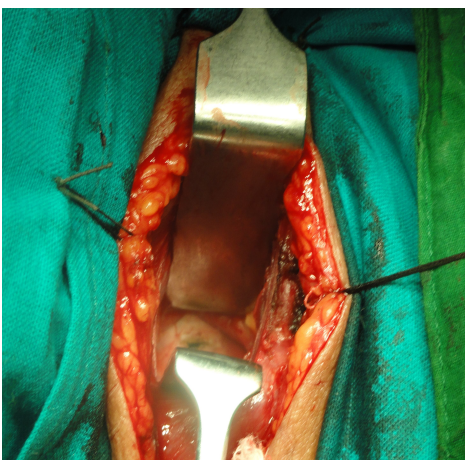

Fig.-3: Peroperative photograph.

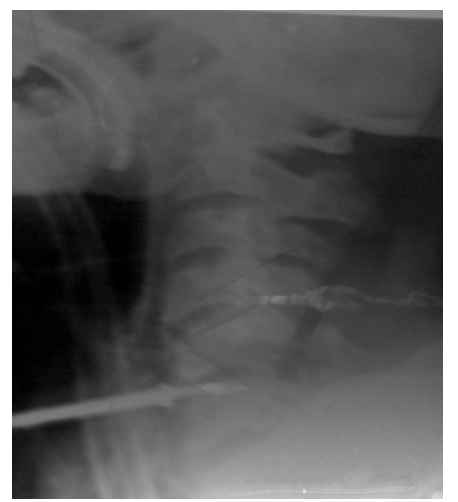

Fig-4: Peroperative marking X-ray with pin at C5-6 level. 


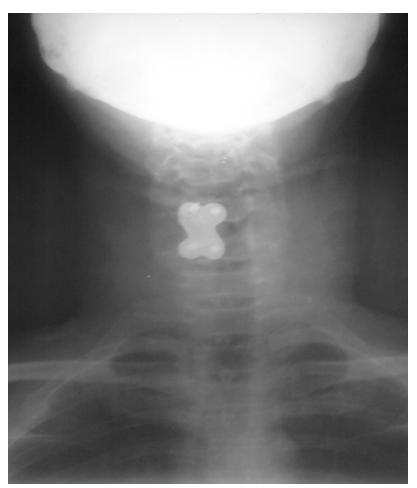

Fig.-5: Postoperative $\mathrm{X}$-ray with plate and screw at C5-6 in A-P view.

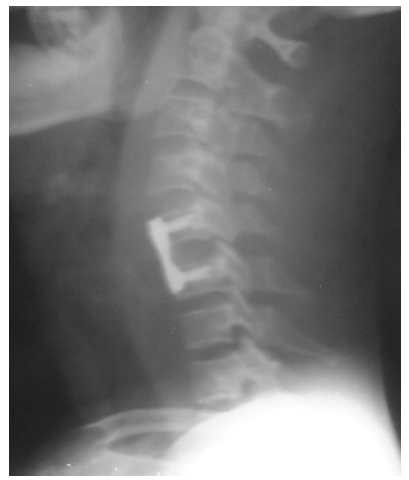

Fig.-6: Postoperative x-ray with plate \& screw at C5-6 in lateral view.

\section{Discussion}

The natural history of CSMR has not been thoroughly defined and documented. Almost all patients worsen if left untreated and most studies report significant numbers (over $50 \%$ ) of patients progressing to severe disability ${ }^{12}$. Indications for instrumentation in these patients are less clear ${ }^{\mathbf{1 3}}$, but the excellent outcome of rigid internal fixation and theoretical advantages of decreasing graft migration have made plating an attractive option ${ }^{\mathbf{1 4}}$. We underwent the same technique and the demographic variables of this series were comparable to $\mathrm{Ali}^{\mathbf{1 5}}$, where male patients were predominant and $\mathrm{C}_{5 / 6}$ level was the commonest involved site. The significant $(\mathrm{p}<0.05)$ clinical improvement (Neck pain, arm pain, motor, sensory and reflex) improvement was comparable to Wang ${ }^{16}$.

According to Epstein ${ }^{17}$ Anterior Cervical Plating (ACP) can maintain lordosis and addition of a ventral cervical plate may add to the security of fixation $^{\mathbf{1 8}}$. Several reports have suggested that rigid internal fixation may be superior to conventional ACDF in patients with $\mathrm{CSMR}^{19}$. Dynamic plate designs provided a faster fusion compared with rigid plate design with lower rate of implant related complications ${ }^{20}$. Hardware failure ranged from 2$44 \%$ in unrestricted back out system whereas only
$0-18 \%$ in locking system with unicortical screws that provided greater screw pullout protection ${ }^{21}$. Although we did not have any hardware failure, an overall screw loosening rate of $24 \%$ has been reported in the literatures ${ }^{22}$.

Connolly $^{23}$ reported fusion rates with autografts ranging from $87-97 \%$, and Emery ${ }^{24}$ reported 20$27 \%$ consistent rate of pseudoarthrosis for anterior discectomy and autogenous bone fusion. The risk of pseudoarthrosis increases with each additional level of surgery ${ }^{23}$. Although we had $100 \%$ fusion and no pseudoarthrosis, the results might have varied with longer follow up and larger study population.

In most reviews, bone graft donor site pain in autogenous bone grafting was reported ${ }^{25}$ mostly due to infection, hematoma, iliac crest fracture and meralgia parasthetica ${ }^{\mathbf{2 6}}$ but we faced it only in 03(18.75\%) patients. Deformity owing to graft subsidence, graft dislodgement, or plate loosening ${ }^{27}$ can occur and it is more problematic with multilevel corpectomy ( 3 or more levels), but it was absent in our series. Casper and Piltzen ${ }^{28}$ reported that graft migration was decreased in multilevel fusions and eliminated in single level fusions. Graft collapse was reported in $20-30 \%$ of multilevel fusion operation ${ }^{29}$.

The literature shows $03 \%$ complication of postoperative dysphonia due to recurrent laryngeal nerve palsy, more on the right $\operatorname{side}^{\mathbf{2 6}}$ but we did not face such problem in any patient. Wound hematoma with airway compromise was found $02 \%-07.30 \%$ in some literatures ${ }^{\mathbf{3 0}}$ but it was also not found in our small series. Incidence of adjacent segment disease was found $02.90 \%$, predicted at 10 years follow up in the literature ${ }^{\mathbf{2 0}}$ but in our short term follow up these complications could not be assessed.

The limitation of the study is that the sample size was small and follow up period was also short to comment largely.

It can be concluded that one or two level ACDF with anterior plating for cervical spondylotic radiculopathy and myelopathy is a safe, effective procedure which provides shorter convalescence and rapid return to activity.

\section{References}

1. Bohlman HH, and Emery SE. The pathophysiology of cervical spondylosis and myelopathy. Spine 1988, 13: 843-6.

2. Dillin WH. Clinical syndromes in cervical myelopathy. In: The Spine. $5^{\text {th }}$ ed. Philadelphia: W.B. Saunders; 2006: 775-88. 
3. Baron EM, Young WF. Cervical spondylotic myelopathy: a brief review of its pathophysiology, clinical course and diagnosis. Neurosurgery. 2007; 60(1 Suppl 1): S35-S41.

4. Abbed KM, Coumans JV. Cervical radiculopathy: pathophysiology, presentation and clinical evaluation. Neurosurgery. 2007; 60(Suppl 1): S28-S34

5. Bailey RW, Badgley CE. Stabilization of the cervical spine by anterior fusion. Am J Orthop. 1960; 42-A: 565-94.

6. Smith GW, Robinson RA. The treatment of cervical spine disorders by anterior removal of the intervertebral disc and interbody fusion. $J$ Bone Joint Surg. [Am] 1958; 40: 607-24.

7. Cloward RB. The anterior approach for removal of ruptured discs. J Neurosurg. 1958; 15: 602-17.

8. Barnes B, Haid RW, Rodts G, Subach B, Kaiser M. Early results using atlantis anterior cervical plate system. Neurosurg Focus 2002; 12(1): Article 13.

9. Heidecke V, Rainov NG, BurkertW. Anterior cervical fusion with the Orion locking plate system. Spine 1998; 23: 1796-802. discussion1803.

10. Mastronardi L, Ducati A, Ferrante L. Anterior cervical fusion with polyetheretherketone (PEEK) cages in the treatment of degenerative disc disease. Preliminary observations in 36 consecutive cases with a minimum 12-month follow-up. Acta Neurochir (Wien). 2006; 148(3): 307-12; discussion 312

11. Guyatt GH, Townsend M, Berman LB, Keller JL. A comparison of Likert and visual analogue scales for measuring change in function. J Chronic Dis. 1987; 40(12): 1129- 33 .

12. Montgomery, D. M. and Brower, R. S. Cervical spondylotic myelopathy. Clinical syndrome and natural history. Orthop. Clin. North Am. 23: 487-493, 1992.

13. 13. Zdeblick TA, Cooke ME, Wilson D, Kunz DN, McCabe R. Anterior cervical discectomy, fusion and plating. A comparative animal study. Spine 1993; 14: 1974-83.

14. Garvey TA, Eismont FJ, Roberti LJ. Anterior decompression, structural bone grafting, and Caspar plate stabilization for unstable cervical spine fractures and/or dislocations. Spine 1992; 17: S431-5.

15. Ali MI, Ahsan K, Awwal MA, Khan RH, Akhond S, Das KP. Treatment of cervical disc prolapsed by anterior cervical discectomy fusion andstabilization with plating. Mymensingh Med J. 2009 Jul; 18(2): 226-31.

16. Wang JC, McDonough PW, Endow KK, Delamarter RB.Increased fusion rates with cervical plating for twolevel anterior cervical discectomy and fusion. Spine 2000 Jan; 25(1): 41-5.
17. Epstein NE. The value of anterior cervical plating in preventing vertebral fracture and strut graft extrusion after multilevel anterior cervical corpectomy with posterior wiring and fusion: indications, results, and complications. J Spinal Disord. 2000; 13: 9-15.

18. Grubb MR, Currier BL, Shih JS, Bonin V, Grabowski JJ, Chao EY. Biomechanical evaluation of anterior cervical spine stabilization. Spine 1998; 23: 886-92.

19. Brown JA, Havel P, Ebraheim N, Greenblatt SH, Jackson WT. Cervical stabilization by plate and bone fusion. Spine 1988; 13: 236-9.

20. Bose B. Anterior cervical fusion using Caspar plating: analysis of results and review of the literature. Surg Neurol. 1998; 49: 25-31.

21. Lowery GL, McDonough RF. The significance of hardware failure in anterior cervical plate fixation. Patients with 2-7year follow-up. Spine 1998; 23:181-6.

22. Epstein NE. The management of one-level anterior cervical corpectomy with fusion using Atlantis hybrid plates: preliminary experience. J Spinal Disord. 2000; 13: $324-8$

23. Connolly PJ, Esses SI, Kostuik JP. Anterior cervical fusion: outcome analysis of patients fused with and without anterior cervical plates. J Spinal Disord. 1996; 9: 202-6.

24. Emery SS, Fisher RS, Bohlman HH. Three-level anterior cervical discectomy and fusion. Spine 1997; 22: $2622-5$.

25. Chen IH. Biomechanical evaluation of subcortical versus bicortical screw purchase in anterior cervical plating. Acta Neurochir. 1996; 138: 167-73.

26. Liao JC, Niu CC, Chen WJ, Chen LH. Polyetheretherketone (PEEK) cage filled with cancellous allograft in anterior cervical discectomy and fusion. Int Orthop. 2008; 32(5): 643-8.

27. Zdeblick TA, Ducker TB. The use of freeze-dried allograft bone for anterior cervical fusions. Eur Spine $J$ 2007; 16: 1689-94.

28. Caspar W, Piltzen T. Anterior cervical plating with single and multilevel fusion in degenerative disease: overtreatment or benefit. Presented at the Tenth European Congress of Neurosurgery, Berlin, Germany, May 27, 1995.

29. Shapiro S, Connolly P, Donnaldson J et al. Cadaveric fibula, locking plate, and allogenic bone matrix for anterior cervical fusion after cervical discectomy for radiculopathy or myelopathy. J Neurosurg. 2001; 95(Supp 1): 43-50.

30. Fountas KN, Kapsalaki EZ, Nikolakakos LG, Smisson HF, Johnston KW, Grigorian AA, et al. Anterior cervical discectomy and fusion complications. Spine 2007; 32: 2310-7. 